\title{
$\mathbf{R}$

\section{OS ESTUDADOS E A PSICANÁLISE EM MOVIMENTOS SOCIAIS}

\author{
Cristiane Izumi Nakagawa ${ }^{1}$ \\ Danielle Teixeira Gimenes ${ }^{2}$ \\ Fabio Carezzato ${ }^{3}$ \\ Paulo Antonio de Campos Beer ${ }^{4}$ \\ Yuri Nishijima Azeredo 5
}

Recebido em: 09/11/2020

Aprovado em: 22/12/2020

Resumo: O objetivo deste artigo é discutir alguns pontos que envolvem o trabalho psicanalítico em situações de vulnerabilidade e violência social. Propostas nessa direção têm ganhado corpo em diversas iniciativas, e daremos foco aqui ao trabalho que vem sendo realizado pelo Núcleo de Estudos e Trabalhos Terapêuticos (NETT). Entre as muitas questões que poderiam ser assinaladas, daremos especial atenção à compreensão dos atravessamentos de questões sociais no processo analítico, em particular o lugar social do saber e sua relação com o estabelecimento da transferência. Será discutido como a circulação da clínica psicanalítica em lugares historicamente não habitados por ela parece simultaneamente demandar o aprofundamento de certas temáticas, e oferecer possibilidades de avanços a outras.

Palavras-chave: Psicanálise; Movimentos Sociais; Saber; Transferência; Humilhação Social.

\section{THE STUDIED ONES AND PSYCHOANALYSIS IN SOCIAL MOVEMENTS}

Abstract: This paper aims to discuss some points related to the psychoanalytic work carried out in situations of social vulnerability and violence. Proposals in this direction have been shaped based on a number of initiatives, being one of them the work done - and which is the focus of

\footnotetext{
${ }^{1}$ Mestra e Doutora em psicologia pelo Instituto de Psicologia da Universidade de São Paulo; Psicóloga social e psicanalista; Coordenadora do Núcleo de Estudos e Trabalhos Terapêuticos (NETT); https://orcid.org/0000-0002-5578-6499._E-mail: cristiane.izumi@gmail.com

2 Psicóloga pela Pontifícia Universidade Católica. Coordenadora do Núcleo de Estudos e Trabalhos Terapêuticos (NETT); https://orcid.org/0000-0003-1204-3561. E-mail: danielle.gimenes@gmail.com

${ }^{3}$ Médico e Psiquiatra pela Faculdade de medicina da USP - PROMUD - Instituto de Psiquiatria - HC - USP. Psiquiatra colaborador. https://orcid.org/0000-0002-1637-2971 E-mail: carezzatofabio@gmail.com

4 Psicanalista, mestre e doutor em Psicologia Social pelo IPUSP. Membro do Laboratório de Teoria Social, Filosofia e Psicanálise (LATESFIP-USP) e da Sociedade Internacional de Psicanálise e Filosofia (SIPP-ISPP). Professor do Instituto Gerar, coordenador do Núcleo de Estudos e Trabalhos Terapêuticos (NETT) e editor de Lacuna: uma revista de psicanálise. Autor de Psicanálise e ciência: um debate necessário (Ed. Blucher, 2017). Contou com bolsa FAPESP para a realização de parte deste artigo (processos 2016/03096-7 e 2018/09753-5). https://orcid.org/0000-0001-9702-4209. E-mail: beerpaulo@gmail.com

${ }^{5}$ Psicólogo, mestre e doutorando no programa de pós-graduação em Saúde Coletiva da FMUSP. Docente do curso de Psicologia da FAM. Coordenador do Núcleo de Estudos e Trabalhos Terapêuticos (NETT). https://orcid.org/0000-0003-2077-0398.E-mail: yuri.azeredo@gmail.com
} 
this article - by the Centre for Studies and Therapeutic Work (NETT). In this context, we will draw special attention to the understanding of the analytical process as well as its crossings by several social issues, in particular the social role of knowledge and its relationship with the establishment of transference. It will also be discussed how the transit of the psychoanalytic clinic in places which are historically not inhabited by it seems to demand a deepening of certain social issues and simultaneously offer possibilities of advance in other themes.

Keywords: Psychoanalysis; Social Movements; Knowledge; Transference; Social Humiliation.

\section{LOS ESTUDIADOS Y EL PSICOANÁLISIS EN LOS MOVIMIENTOS SOCIALES}

Resumen: El propósito de este artículo es discutir algunos puntos que involucran el trabajo psicoanalítico en situaciones de vulnerabilidad y violencia social. Propuestas en esta dirección surgen en varias iniciativas, y aquí nos centraremos en el trabajo que está desarrollando el Centro de Estudios y Trabajos Terapéuticos (NETT). Entre las múltiples cuestiones que podrían destacarse, prestaremos especial atención a la comprensión de los cruces de las cuestiones sociales en el proceso analítico, en particular el lugar social del conocimiento y su relación con el establecimiento de la transferencia. Se discutirá cómo la circulación de la clínica psicoanalítica en lugares históricamente no habitados por ella parece demandar simultáneamente la profundización de ciertos temas y ofrecer posibilidades de avance a otros.

Palabras-clave: Psicoanálisis; Movimientos sociales; Saber; Transferencia; Humillación social.

\section{O NÚCLEO DE ESTUDOS E TRABALHOS TERAPÊUTICOS (NETT)}

O Núcleo de Estudos e Trabalhos Terapêuticos (NETT) foi fundado em fevereiro de 2019 com o objetivo de oferecer atendimento clínico psicanalítico, psiquiátrico e atividades terapêuticas gratuitas a pessoas que sofrem com violência social, além de formação em psicanálise com foco nestas práticas. Parte-se da compreensão de que onde há sofrimento psíquico, há uma contribuição possível da parte da psicanálise; portanto, é possível haver um psicanalista fazendo a escuta. É uma proposta que visa a democratização do trabalho psicanalítico, tanto em sua faceta terapêutica como em seu potencial de compreensão e intervenção em questões sociais. Isso se faz necessário uma vez que a circulação da psicanálise é tradicionalmente restrita, estando ausente em diversos territórios que poderiam ser beneficiados por ela. Nesse sentido, visamos ampliar a oferta de escuta e formação não somente enquanto propostas terapêuticas, mas também como formas de implicação política da psicanálise, da psicologia social e da psiquiatria no momento sociopolítico atual.

A atuação do núcleo engloba, também, a criação de uma rede de parcerias com instituições de formação em psicanálise e universidades, de modo a ampliar a equipe de psicanalistas, psicólogos clínicos e psiquiatras. Esse movimento teve início a partir de 
uma grande demanda primeiramente proveniente de militantes e pessoas ligadas ao Movimento dos Trabalhadores Sem-Teto (MTST), e depois de outros movimentos sociais que igualmente possuem acesso restrito a cuidados na área psíquica. Para isso, foram formadas parcerias com psicanalistas e instituições interessadas em compor essa rede $^{6}$, além de firmados acordos para atendimento e oferta de formação para diferentes movimentos sociais ${ }^{7}$.

\section{A INSEPARABILIDADE ENTRE CONFLITO SOCIAL E CONFLITO PSÍQUICO}

A atuação clínica do NETT envolve a oferta de atendimentos terapêuticos voltados para uma população que vive em condições de violência social, em particular aqueles que estão articulados em movimentos sociais. Essa especificidade (o foco em membros e ativistas ligados a movimentos sociais) parte da compreensão de que o sofrimento psíquico não deve ser limitado à sua dimensão individual. Ao contrário, sua localização e implicação da produção de sofrimento em modos particulares de organização social (Safatle, Dunker, Silva Jr., 2018) indica não somente os limites de uma abordagem estritamente individual, mas também a obliteração da dimensão política do sofrimento (Frosh, 2019, Beer, 2020), frequentemente esquecida.

Essa dimensão política do sofrimento é tomada enquanto um ponto de inflexão, a partir do qual o horizonte clínico deve se reorganizar para oferecer a possibilidade de atuação na causa do sofrimento. Trabalha-se com o entendimento de que processos terapêuticos devem ser também práticas críticas que reconhecem e se opõem a mecanismos de produção e reprodução de segregação e violência.

A oferta terapêutica não pode, assim, limitar-se à redução ou alívio de sintomas; deve, isso sim, consistir em práticas habitadas por projetos calcados em ideais de transformação radical, tanto dos sujeitos como do mundo em que vivem. Horizonte largamente partilhado com os movimentos parceiros, de modo que as atividades oferecidas pelo núcleo apresentam um potencial multiplicador. Esse tipo de parceria

\footnotetext{
${ }^{6}$ Entre as parcerias institucionais, pode-se mencionar o Instituto de Psicologia (IPUSP) e o Laboratório de Teoria Social, Filosofia e Psicanálise (LATESFIP), ambos da Universidade de São Paulo; a Pontifícia Universidade Católica de São Paulo; e o Núcleo Acesso do Instituto Sedes Sapientiae.

${ }^{7}$ Atualmente, há acordos firmados com os seguintes movimentos: Movimento dos Trabalhadores SemTeto (MTST); APOIO - Frente de Luta por Moradia; Projeto Antônia; e Amazônia Centro do Mundo.
} 
também se mostra profícua pelo potencial terapêutico dos próprios movimentos sociais, o que pode ser compreendido pelos efeitos de pertencimento muitas vezes experienciados por seus membros (Boulos, 2017).

Contudo, apesar de ser possível reconhecer diversos pontos de confluência, a realização desse trabalho é usualmente atravessada por diversos conflitos, os quais podem ser compreendidos como efeitos de contradições entre modos e lugares de circulação tradicionalmente imputados à psicanálise e seus efeitos numa sociedade marcada por uma desigualdade tão profunda, como a brasileira.

Isso indica, de partida, a necessidade de reconhecimento de marcadores sociais, ou mesmo de marcadores sociais da diferença (Castro, 2011), para a construção da possibilidade de trabalho clínico. Isso se evidencia no fato de que, na escuta clínica feita pela coordenação e equipe do NETT, é possível identificar temas em comum independente do movimento social: a falta de acesso a saúde de qualidade, moradia irregular, abuso sexual, violência de gênero, alcoolismo, trabalho precarizado, entre outros. A repetição de experiências pautadas na negação de direitos demonstra um marcador de classe social que deve ser levado em consideração ao pensarmos criticamente a saúde mental, não nos limitando a um recorte restrito a classes privilegiadas.

Neste sentido, o conceito de "humilhação social" utilizado pelo psicólogo José Moura Gonçalves Filho (1998) pode nos auxiliar a compreender, primeiramente, a relação entre os demarcadores sociais de diferença entre classes e o sofrimento psíquico que se apresenta na clínica. Este fenômeno psicológico nada mais é do que um sentimento de angústia, que ao contrário de ser o mais indefinido dos afetos, aponta suas origens mórbidas ligadas à dominação e a um entendimento da pobreza como algo inferior. Segundo Gonçalves Filho (1998), um olhar, uma palavra, um tom de voz, entre muitos outros, são gestos que carregam em si e transmitem índices de humilhação, desprezo, rebaixamento, que fazem inscrever na pessoa que os recebe um forte enigma, o qual é fonte interminável de angústia. O que se depreende imediatamente dessa constatação é que o sofrimento não pode ser apartado dos atravessamentos sociais em que se faz presente.

De fato, a relação entre psicopatologias e fatores sociais não é cientificamente nova, tampouco estranha à psicanálise. Entretanto, parece haver um certo privilégio de 
discussões que focam no caráter necessário do mal-estar enquanto um produto da cultura ou da civilização. Isso acontece em detrimento de análises que discutem que o modo como a produção de sofrimento, sintomas e mal-estar varia de acordo com as regras sociais. Se essa primeira abordagem é tradicionalmente imputada ao célebre "O mal-estar na civilização" (Freud, 1930), é preciso lembrar que mais de 20 anos antes o próprio Freud tecia comentários que não se limitavam ao adoecimento inevitável dos processos civilizatórios, mas também ao modo como isso poderia ser agravado ou atenuado. É o que aparece, por exemplo, em “Moral sexual 'cultural' e o nervosismo moderno" (Freud, 1908), texto que, se por um lado afirma o caráter patogênico geral de processos sublimatórios, também faz duras críticas à cultura europeia da época, indicando que o abandono de certos padrões normativos de regulação da sexualidade atenuaria a produção de sofrimento ao diminuir a carga de renúncia pulsional demandada dos indivíduos.

Essa linha argumentativa pode, entretanto, ser extrapolada a outros tipos de impacto da organização social na vida psíquica, não se limitando a restrições diretamente direcionadas à vida sexual. Tal alargamento pode ser encontrado num trabalho conceitual do próprio Freud, seja na indicação dos atravessamentos culturais presentes na determinação da constituição dos sintomas (Freud, 1917/2014), seja na amplitude do alcance daquilo que pode ser compreendido enquanto um "processo sublimatório". Sobre isso, pode-se remeter a dois pontos presentes em "O eu e o Id" (Freud, 1923/2011): primeiramente, à compreensão da sublimação enquanto um processo de deserotização, ou seja, de reorganização pulsional a partir da interdição dos objetos investidos (lembremos que, nesse momento, Freud já trabalha com o complexo de Édipo composto, ou seja, o investimento não se limita a apenas um objeto). Nesse sentido, a deserotização seria, para além de uma consequência da instauração de uma proibição, a gênese de movimentos identificatórios, os quais podem ser vistos enquanto parte necessária ao enlaçamento social (Freud, 1921/2011). Junto a isso, Freud também apresenta, nesse momento, uma explicação mais complexa do caráter patogênico desses processos, agora pensados a partir da dualidade pulsional: a deserotização produziria um "resto" de pulsão de morte decorrente da defusão pulsional, o qual ou ganha um destino exterior ou é alocado internamente como agressividade dirigida ao próprio eu (entre outras possibilidades). 
Uma visão panorâmica desses trabalhos permite articular a ideia presente em "Moral sexual..." para além de normas que incidem diretamente na regulação da sexualidade, indicando que mesmo que todo processo social contenha um sofrimento inerente, isso não se dá de igual maneira em todas as culturas. É possível, dependendo da organização social, que esse sofrimento seja parcialmente elaborado, que ele tenha destinações socialmente aceitas, ou então que ele não seja tratado ou se quer reconhecido e, assim, os prejuízos decorrentes deles sejam aprofundados (Dunker, 2016, Hacking, 1998). Ou seja, não se trata somente de se entender o processo civilizatório como intrinsecamente produtor de mal-estar; trata-se também de pensar que a intensidade, as possibilidades de elaboração e destinação, assim como os silenciamentos e as violações resultantes da deslegitimação de formas de sofrimento sejam também pensadas enquanto subprodutos de modos específicos de organização social (Safatle, Dunker \& Silva Junior, 2018).

Nesse sentido, a experiência da humilhação, tal como conceituada por Moura (1998), mostra esse duplo aspecto da internalização individual da experiência socialmente determinada. Nela, o rebaixamento político (Moura, 1998) passa a ser vivido pelo oprimido como algo interno a si, incapaz de se reconhecer nos outros, ou no meio dos outros. A própria potência de ação no mundo se desfaz na medida que o sujeito é abatido por esta força enigmática. Este abatimento, aqui localizado na relação dialética, é internalizado a ponto da condição proletária ser algo automática e, inicialmente, de impossível enfrentamento. A espontaneidade do oprimido, como indica Neusa Santos (1983), é um direito negado para que haja sempre a possível defesa do ataque, da violência e da discriminação.

Por um lado, tem-se os impactos diretos na saúde mental da falta de acesso a direitos previstos na Constituição como referido anteriormente, por exemplo: saneamento básico, moradia, cultura, lazer, segurança, entre outros. Por outro, os oprimidos passam a proferir discursos de autoculpabilização que justificam a contínua subordinação social (González \& Hasenbalg, 1982). O Estado, teoricamente responsável pelo cuidado e pela possível reparação de exclusão histórica e estrutural, corrobora com a individualização na permanência de um discurso homogêneo das classes dominantes. Torna-se, portanto, cúmplice de uma narrativa meritocrática em que dependeria apenas do indivíduo ascender socialmente para acessar direitos básicos menos precários. 
A angústia que advém da humilhação se dá no impedimento do compartilhamento social. O ponto de encontro desta linha tênue entre mundos, isto é, entre classes, é o que Moura (1998) remete ao sentimento de "despencamento" ou "angústia de cair", esta última apresentada na clínica winnicottiana. É neste ponto que se inscrevem os enigmas criados e mantidos nas relações intersubjetivas, que geram a angústia na impossibilidade de alcançar, pelo oprimido, o ponto inicial deste mal-estar que carece de representação psíquica.

Um exemplo claro da intersecção entre desigualdade, humilhação e invisibilidade das questões sociais é a saúde mental da população negra, que são $75 \%$ entre os mais pobres (IBGE, 2019). As repetidas exposições à violência racial também levam a processos adoecedores. Os sujeitos oprimidos sentem vergonha de sua condição e passam a criar estratégias de “ocultamento" (González \& Hasenbalg, 1982). A negação dessa condição se cria ao tomar o lugar social do branco como lugar social a ser alcançado. Psicanaliticamente falando, o branco é vivenciado como ideal de Ego (Santos, 1983) e, seu alcance sendo impossível, sentimentos de culpa e inferioridade, insegurança e angústia são vivenciados pela população negra.

Neusa Santos (1983) entende que o ocultamento deste mal-estar consiste também num modo de não elaboração dos próprios recalcamentos do sujeito que sofre:

A nível clínico, esta relação de tensão toma o feitio de sentimento de culpa, inferioridade, defesa fóbica e depressão, afetos e atitudes que definem a identidade do negro brasileiro em ascensão social como uma estrutura de desconhecimento/reconhecimento (SANTOS, 1983, p. 78)

Quando falam, não são escutados e, quando são minimamente escutados, lhe são receitados medicamentos que afastam a possibilidade de aproximação do enigma. Neste sentido, o próprio saber sobre si é dificultado pelo aspecto econômico e social que se vivencia. A autonomia de construção de identidade é minada pela necessidade de ascensão social para reconhecer-se no outro, tornar-se visível, tornar-se, enfim, gente (Santos, 1983).

Uma das consequências desse processo pode ser a produção de modos de sofrimento como a depressão. Boulos (2017), por exemplo, afirma que a depressão é a própria defesa do sujeito diante do desamparo. Kehl (2009) confirma ao entender a 
depressão como "a invasão do Real sobre o psiquismo que não dispõe de recursos de linguagem para simbolizá-lo é chamada pela psicanálise de trauma" (p. 160).

O desenraizamento, termo cunhado por Simone Weil e utilizado por Moura no fenômeno de humilhação social, complexifica o entendimento crítico do impacto social na saúde mental. Para a autora francesa (Weil, 2001), a perda das raízes diz respeito ao fenômeno contemporâneo na qual o indivíduo torna-se incapaz de se sentir pertencente e participar de dada coletividade.

A OMS reconhece que a propensão de se desenvolver depressão é maior em situações de pobreza, onde a vida é tecida de forma prática e carece de "fantasias a respeito do devir" (Kehl, 2009). Se o enraizamento pode ser entendido na medida que o sujeito existe e atua no mundo (Moura, 1998), o desenraizamento é o oposto: viver, apenas, não pressupõe participação no mundo que se vive. Experienciar onde se vive pressupõe compartilhar um comum, onde se conserva um passado compartilhado e se compartilha, no presente, a perspectiva de um futuro também comum. Isto é, no comum, as dores da alma tornam-se dignas a ponto de humanizar-se no vínculo com o outro. No comum, o devir é produção de saúde.

Vemos, desse modo, que não somente é incorreto pensar o sofrimento como algo apartado das condições sociais de sua produção, mas que também as próprias propostas terapêuticas não podem ser dissociadas de modificações de cada sujeito no enlaçamento social e na construção do comum. Contudo, essa compreensão não parece ser algo presente no discurso terapêutico que circula de maneira hegemônica atualmente (Furedi, 2004; Rose, 2018), e isso traz consequências diretas para a possibilidade de realização de trabalhos clínicos nesses moldes. É disso que trataremos a seguir.

\section{A PSICANÁLISE E OS “ESTUDADOS”}

Após essa breve exposição sobre a inseparabilidade entre conflito psíquico e conflito social, podemos localizar a inserção do trabalho do Núcleo e algumas problemáticas incontornáveis. O trabalho do NETT tem como ponto de partida um trabalho de acompanhamento psicológico e trabalhos terapêuticos realizado a partir de 2017 na ocupação do MTST, Vila Nova Palestina, trabalho este iniciado a pedido de 
lideranças do movimento. A princípio, a preocupação era de que haveria uma demanda muito elevada, mas durante as primeiras semanas de trabalho não houve nenhum pedido de atendimento por parte dos moradores ou militantes daquela ocupação, o que provocou uma certa frustração por parte da equipe designada naquele primeiro momento. Isso levou a uma importante reflexão sobre as possibilidades e limites que um trabalho como o que estava sendo proposto deveria reconhecer para que pudesse prosperar naquele território.

Naquele momento, e no contexto daquelas reflexões, um episódio foi de fundamental importância: em um dos dias de atendimento, ao chegar à ocupação Vila Nova Palestina, a porta do barracão encontrava-se trancada. Semanalmente, um coordenador da ocupação abria a porta para a equipe, mas naquele dia, o mesmo teve um imprevisto e não estava no local no horário combinado. Frente àquela situação, a equipe decidiu não ir atrás da chave, e pensou que talvez fosse uma oportunidade para se familiarizar com as pessoas que moravam ali. Começaram a caminhar pelas pequenas e estreitas ruelas que separavam os barracos dos moradores e das pessoas que lutam por moradia naquele terreno, e ao encontrarem as pessoas, as cumprimentavam buscando estabelecer algum tipo de conversa. Pela primeira vez aconteceram três conversas no intervalo de 3 horas que estiveram na ocupação e, portanto, decidiram que, na semana seguinte (e em quantas mais fossem necessárias), iriam andar pela ocupação com a intenção de fazer contato com os moradores. Muita gente passou a observá-los com certa desconfiança, e em troca, os psicanalistas devolviam-Ihes um sorriso, um cumprimento oral, um aperto de mão, um abraço acompanhado de apresentações. Passaram a provocar conversas, trocar receitas, brincar com as crianças, e assim, configurou-se o trabalho inicial naquela ocupação. Após algumas semanas ficou claro que, naquele primeiro momento, eram os psicanalistas que queriam ouvi-los e não o contrário.

Aos poucos, os analistas foram deixando de ser figuras forasteiras e passaram a estar familiarizados com o local e com as pessoas e, mais importante, as pessoas estavam mais familiarizadas com aquelas figuras estrangeiras. Convites para café, bolo, chá começaram a ser recebidos e, na privacidade dos barracos, as pessoas começaram a falar de suas vidas e de seus problemas, ou seja, o trabalho de escuta começara a tomar forma. 
Nesse ponto, foi fundamental o pensamento acerca do papel do 'forasteiro' naquele cenário, que é visto com muita desconfiança, pois é associado àquele que chega para impor um certo catecismo cultural. Esse pensamento foi apoiado pelas conversas abertas - fora do contexto de atendimento - sobre a questão da "língua" que marcava um lugar social. Esses relatos expunham a dificuldade, num primeiro momento, de compreender e, portanto, de acompanhar algumas reuniões ou informes quando esses eram realizados por pessoas que usavam palavras mais "difíceis". Reclamavam sobre o quanto era difícil conversar com os outros e principalmente falar com os "estudados" que chegavam como colaboradores do MTST - a gentileza não os permitiu falar diretamente, mas em outros momentos ficou claro que os psicanalistas estavam entre os "estudados" - e foi uma das muitas justificativas (pensadas em grupos com as pessoas daquela ocupação) do porquê que o barracão ficava vazio nas primeiras semanas após nossa chegada.

Dessas conversas ficou claro que não entender o que os "estudados" falam é marcar um lugar de desigualdade, de humilhação social. Quando a hipótese foi levantada em uma das rodas de conversa, um dos companheiros riu e comentou que todos deveriam ser como "o Guilherme, que fala todas as línguas da periferia". Ainda rindo, disseram que a periferia tem muitas línguas, e não somente àquela oral, mas também aquela dos gestos, atitudes e olhares. Nesse contexto, a equipe comentou que passou pelo mesmo estranhamento quando fez as primeiras reuniões com a coordenação do movimento: não compreendeu metade das coisas que foram ditas: siglas, gírias, conteúdos sobre a estrutura do movimento, ou outras de questões mais da ordem pessoal de cada orador. Eles riram, dizendo que aquilo só poderia ser uma brincadeira, mas cessaram quando uma das psicanalistas afirmou que não apenas não compreendera metade da reunião, mas que se sentira constrangida em perguntar e mostrar que de fato não havia entendido e acompanhado o encontro. Acrescentou ainda que seu silêncio, aquele referente à recusa de perguntar o que significavam todas aquelas palavras, gírias e siglas, era devido a uma arrogância por achar que, por ser uma dos "estudados", deveria ter compreendido tudo e não desejar perguntar era uma forma de não abandonar esse suposto lugar de "saber". Esse tema foi debatido em muitas outras ocasiões dentro da ocupação. 
A partir de então, sempre que a equipe perguntava o que queria dizer uma palavra ou ouvia algo que não compreendia, sua pergunta era recebida com surpresa e sorriso, mas nunca um sorriso desmoralizante, e sim, familiar, solidário, como se ali surgisse um "estudado", não no analista, mas em quem poderia explicar algo que ele não entendera. Explicavam alegremente os significados das coisas e palavras, e se fosse comida ou bebida, ainda providenciavam para que na semana seguinte os psicanalistas pudessem experimentar.

\section{SABER, TRANSFERÊNCIA, RESISTÊNCIA E VIOLÊNCIA}

Nesse ponto é possível retornar à teoria psicanalítica e ao que foi apresentado sobre a inseparabilidade entre individual e coletivo, de modo a situar as problemáticas encontradas. Isso porque, como demonstra a experiência clínica, há um tipo de problema colocado pela desigualdade social que faz com que o próprio saber seja vivenciado numa inscrição dupla: enquanto algo que pode trazer contribuições, ao mesmo tempo que se apresenta enquanto uma forma de violência e humilhação social. Algo que pode ser compreendido não somente no acesso desigual à educação - o qual, como bem dizia Darcy Ribeiro, trata-se de um projeto e não de um desvio -, mas também no que essa diferença de acesso representa na sociedade brasileira. Uma rápida lembrança do tipo de oposição que a implementação do sistema de cotas sofreu (e ainda sofre) remete ao fato de que a educação não é compreendida enquanto um direito, mas sim como uma marca que diferencia classes sociais (Castro, 2011; Moutinho, 2014).

A presença desse tipo de marcador é justamente um dos modos de operação da supracitada humilhação social (Gonçalves Filho, 1998), uma vez que são marcas permanentemente presentes nos discursos e instituições, e que reafirmam um modo de organização social estruturado na segregação e na violência. Desse modo, o encontro com demonstrações de saber ou simplesmente com pessoas que tiveram acesso àquilo interditado à grande maioria da população constitui o encontro não só com a desigualdade, mas com a violência que estrutura a sociedade. Frente $a$ isso, a psicanálise oferece diversos instrumentos para o tratamento desse sofrimento, trabalhando com um horizonte não somente de alívio sintomático, mas sim de um tipo de transformação que engloba também o modo de enlaçamento de cada sujeito. Contudo, como 
apresentado anteriormente, parece haver uma questão inicial, um problema para o estabelecimento da própria possibilidade de um processo terapêutico que não pode ser negligenciado.

Esse problema se coloca de maneira tão radical porque o saber constitui um elemento central na possibilidade de tratamento. Como afirmava Jacques Lacan, o motor de uma análise (definido por Freud no conceito de transferência) seria justamente uma "suposição de saber" (Lacan, 1967). Isso engloba, portanto, não somente algo constituído a partir daquilo que efetivamente faria parte da formação do analista, mas também aquilo que o analisante supõe sem saber se realmente corresponde à realidade. Mais precisamente, a suposição de saber diria respeito, no limite, à demanda de que um outro saiba daquilo que o próprio sujeito não quer saber - indicando, como já colocava Freud, a dimensão de resistência presente no próprio funcionamento transferencial (Freud, 1914). Numa leitura lacaniana, portanto, o saber seria um operador necessário, já que seria a sua suposição que permitiria a transferência e a associação-livre, permitindo assim o trabalho analítico.

Contudo, o que se vê é que esse próprio operador, que permitiria a abertura da fala e que seria mobilizado na instauração da associação-livre, pode ter um efeito contrário. Pois, em situações marcadas por segregação e humilhação social, a reiteração do saber enquanto um marcador de diferença e produtor de violência pode produzir não a abertura, mas sim o silenciamento.

Pode-se lembrar que essa temática foi abordada por Lacan, embora num debate contingencialmente distinto. Em seu seminário sobre Os escritos técnicos de Freud (Lacan, 1953-54/1986), o filósofo francês Jean Hyppolite coloca uma questão sobre o potencial de dominação da clínica psicanalítica, retomando a diferenciação feita por Freud (1914) de que a perlaboração da resistência consistiria no trabalho de um sujeito, enquanto o desvio da resistência (imputado por Freud à hipnose) deixaria o paciente numa posição objetificada. Hyppolite, retomando reiteradas críticas sobre a possibilidade do uso do conceito de resistência como uma espécie de blindagem do analista em relação a seus próprios erros, questiona se não seria possível pensar que a opressão de um sujeito pela teoria psicanalítica seria algo ainda mais agressivo do que a opressão a um objeto (remetendo à ideia da objetificação presente na hipnose). 
De fato, essa temática é recorrente no campo psicanalítico, algo que fez com que Freud dedicasse um cuidado especial a essa questão em "Construções em análise" (Freud, 1937/2018). Segundo o psicanalista, tomar o conceito de resistência enquanto um subterfúgio para que o analista não seja colocado em questão seria um erro de compreensão, especialmente considerando-se o que se deve fazer frente à resistência. Freud retoma, para tanto, a discussão sobre o estatuto da negação em psicanálise, a qual já fora complexamente trabalhada em A negação (Freud, 1925/2014). Em 1937, o psicanalista diferencia tipos distintos de negação, incluindo um primeiro que diria respeito aos possíveis erros do analista. Contudo, tomar a negação em todos os casos como um erro seria equivocado porque, usualmente, a negação seria uma resposta inconsciente articulada ao recalque, operando como um elemento defensivo com o intuito de distanciamento da causa da angústia. Nesse sentido, isso seria um indicador do êxito de uma construção ou de uma interpretação, uma vez que Freud entende que a produção de uma resposta inconsciente seria justamente o efeito pretendido.

A problemática em relação ao mau uso do conceito de resistência residiria, portanto, ou numa má interpretação sobre a resposta recebida, ou sobre o modo de atuação em relação à resistência. É preciso lembrar que já em 1914 Freud afirmava que a resistência e, especialmente, a transferência - apontada como o ponto máximo da resistência - apresentam um limite sobre a possibilidade de interpretação, colocando o analista numa posição de inocuidade em relação a suas possibilidades de intervenção. Como afirma Freud, nesses momentos é

preciso dar tempo ao paciente para que ele se enfronhe na resistência agora conhecida, para que a elabore, para que a supere, prosseguindo o trabalho apesar dela, conforme a regra fundamental da análise. Somente no auge da resistência podemos, em trabalho comum com o analisando, descobrir os impulsos instintuais que a estão nutrindo, de cuja existência e poder o doente é convencido mediante essa vivência. (Freud, 1914/2010, p.209)

Vê-se, portanto, que posicionamentos confrontadores ou opressivos não parecem ter lugar, ao menos não nesses momentos. Ao contrário, há a proposição de uma espécie de recuo (até mesmo de certa horizontalidade) na ideia de dar tempo ao 
paciente e de que analista e analisando fariam um trabalho comum. Fica claro que há uma preocupação com a possibilidade de opressão por parte do analista.

Contudo, essa diretriz freudiana parece não resolver a questão, o que fica evidente em seus diversos retornos posteriores. Isso pode ser entendido pela hipótese de uma má leitura dos escritos freudianos, ou então por ser efeito de um tensionamento incontornável entre o saber teórico e a prática clínica. A segunda opção foi largamente trabalhada por Sandor Ferenczi (1930/1992), em sua crítica ao modo como uma relação cristalizada com a teoria traria grandes prejuízos para a escuta clínica.

Como indicam Osmo \& Kupermann (2012), é possível retomar a proposição ferencziana de uma confusão de línguas (Ferenczi, 1933/1992), sem limitá-la à relação entre adultos e crianças, também na relação entre analista e analisando. $O$ grande prejuízo desse funcionamento seria justamente a resolução do tensionamento entre as diferentes línguas, na qual o lado mais poderoso se sobreporia ao desmentir o que é dito pelo lado mais fraco. Se aplicado à situação analítica, o que se tem é que essa sobreposição se faria possível a partir do desbalanço de poder causado pela diferença em relação ao saber, o que seria aprofundado quanto mais o psicanalista encaixasse aquilo que escuta na teoria estabelecida, sem espaço para crises. O desmentido é apontado por Ferenczi como parte principal do trauma, pois seria causa de silenciamento e impossibilidade de elaboração (Osmo \& Kupermann, 2012).

Retomando a questão colocada por Hyppolite, é possível notar que a tensão aludida entre o potencial reificante da teoria psicanalítica continua presente duas décadas após os apontamentos do psicanalista húngaro. Também se pode reconhecer que o encaminhamento dado por Lacan se aproxima dos incômodos apontados por Ferenczi em diversos pontos.

O modo como Lacan destina a questão é bastante amplo, e intensamente habitado pelas críticas marxistas de Georges Politzer à metapsicologia freudiana (Politzer, 1928/1998; 1939/2017). Isso significa que Lacan enfrenta o apontamento de Hyppolite aludindo ao caráter libertador da psicanálise, e desdobra a questão da resistência dentro de uma reorganização conceitual já em curso. Nesse momento específico, além de tecer duras críticas a grupos pós-freudianos que teriam um entendimento errado do conceito de resistência (e, em consequência, das linhas que localizariam a "análise das resistências" como elemento central da prática analítica), 
Lacan delineia uma compreensão do que seria a interpretação psicanalítica a partir de uma abordagem particular da questão do saber.

Carregando também uma forte influência hegeliana, Lacan já trabalhava com um tensionamento entre saber e verdade, sendo que o primeiro poderia ser encarado enquanto formas cristalizadas e alienantes, enquanto a verdade seria apontada como o ponto em torno do qual orbitaria uma análise (Lacan, 1951/1998). Anos depois, Lacan exporia sua célebre fórmula de que "Eu, a verdade, falo" (Lacan, 1955/1998), num texto em que a verdade seria apresentada não somente como dotada de enunciação própria, mas também como aquela que fala nos sonhos, atos falhos, entre outros. Ou seja, há uma clara localização da verdade enquanto elemento central da clínica psicanalítica.

Essa centralidade, entretanto, se dá em oposição ao saber. E, nesse sentido, o saber pode ser compreendido tanto como narrativas alienantes do indivíduo sobre ele mesmo (as quais seriam tensionadas ou desconstruídas pela emergência da verdade), quanto na estabilização teórica do que acontece na clínica. Ou, ainda mais explicitamente, o tensionamento entre esses dois termos se mostraria em sobreposições da teoria à escuta. O exemplo que mobiliza nas sessões seguintes à intervenção de Hyppolite traz à cena um relato de caso de Ernst Kriss, em que uma interpretação realizada pelo analista sobre o sintoma do paciente é entendida por Lacan como um ato de silenciamento por parte do analista, e que teria levado o paciente a um acting-out.

Segundo o psicanalista francês, o grande problema não estaria na correção ou não do conteúdo da interpretação, mas sim no modo como o saber havia sido mobilizado, sobrepondo-se à possibilidade de escuta de algo da ordem do desejo do paciente. Algum tempo depois, Lacan retoma esse caso para proferir sua famosa afirmação de que a resistência está sempre do lado do analista (Lacan, 1958/1998), a qual pode ser desdobrada na compreensão de que o recurso à teoria analítica pode ser, ele mesmo, uma forma de resistência. Uma forma do analista não escutar algo que ele mesmo preferiria evitar. Reafirma-se, assim, a primazia da escuta na prática clínica, apontando-se o cuidado que se deve ter com o emprego da teoria. Mais que isso, a própria ideia de interpretação ganhará um sentido radicalmente ligado à abertura da fala, cultivando-se um tensionamento constante entre saberes estabelecidos e a verdade inconsciente. 
Vê-se, portanto, que os modos de uso da teoria psicanalítica sempre suscitaram questionamentos sobre os efeitos do emprego do saber no contexto clínico. Vemos isso nos poucos exemplos mobilizados (certamente é possível encontrar movimentos semelhantes em diversos outros autores), seja pela inocuidade da insistência do saber em situações de resistência extrema (Freud), o caráter traumático de seu uso enquanto produtor de um desmentido (Ferenczi) e o reconhecimento de interpretações que estabilizam um saber enquanto algo que atrapalha o processo analítico (Lacan).

São apontamentos que, embora incontornáveis na prática clínica, não parecem resolver a questão que colocamos anteriormente e que disparou essa discussão. Isso porque esses desenvolvimentos dizem respeito a questões encontradas em processos clínicos já estabelecidos, enquanto o problema que colocamos diz respeito a algo anterior. De onde se pode retornar à questão: como lidar com o fato de que o mesmo operador que possibilita a associação-livre via transferência também produz silenciamento?

Essa questão ganha consistência agora, pois retomando o conceito de humilhação social e o episódio relatado sobre como o estudo e o saber podem ser localizados enquanto marcadores de uma violência social vigente, as possibilidades de intervenção devem ser deslocadas para um momento anterior. Fica claro que há um silenciamento operante num momento inicial, que não diz respeito somente ao que Freud chamaria de resistência, mas sim a um modo de organização social. Isso pode ser encarado, como apontado anteriormente, como um efeito da desigualdade de oferta de educação e pela localização dos estudos não como um direito, mas como uma marca social ligada a pertencimento de classe (Moutinho, 2014; Seffner \& Moura, 2019): algo que seria, portanto, interditado às classes marginalizadas e que instauraria, consequentemente, um efeito de deslegitimação da fala desses sujeitos. Trata-se, portanto, de algo anterior ao que é tradicionalmente discutido na psicanálise, e diz respeito às condições de possibilidade de instauração da transferência.

\section{CONCLUSÃO}

Talvez o modo como a própria questão se encaminhou no caso relatado possa indicar um caminho possível de enfrentamento dessa questão. Isso carrega a 
peculiaridade de não se tratar de um tipo de elaboração e operação sobre a suposição de saber dentro do setting analítico tradicional, mas sim de elaborações realizadas em espaços coletivos. Isso indica não somente a supracitada inseparabilidade entre social e individual, mas também a necessidade de reconhecer que a própria possibilidade de trabalho psicanalítico envolve um exame dos discursos sociais presentes e do lugar que a psicanálise ocupa neles.

Talvez a consideração dessa dimensão não se faça urgente ou relevante em contextos em que esses lugares sociais não produzam conflitos. É possível, por exemplo, que a limitação histórica da psicanálise brasileira a classes privilegiadas (com algumas exceções, evidentemente), possa ter contribuído para a obliteração desse problema. Não deixa de ser, efetivamente, o cerne da problemática discutida: afinal, como seria possível realizar um projeto clínico que não seja colonizador, dado que a própria constituição da psicanálise, mesmo que carregue um potencial de tensionamento, também não deixa de ser um produto de projetos colonizadores. O que nossa experiência mostra, assim como a de diversos outros grupos que têm se engajado em movimentos similares, é que isso é possível a partir do reconhecimento dessa história e da abertura à transformação do lugar da psicanálise na cultura. Ideia que não pode ser considerada nova (Danto, 2019), embora padeça de aplicações bem-sucedidas.

Retornando ao relato, podemos ver que o trabalho proposto foi se delineando ao longo dos meses e anos de atuação dentro da ocupação, e talvez tenha sido apenas possível avançar e continuar porque dentro e fora dali ocorreram muitas discussões sobre os temas da dominação e da humilhação social, fazendo do trabalho psicanalítico que se desenhava naquele espaço um oposto àquele colonialista: não se tratou de um forasteiro que chegou para impor sua cultura e língua - se esse tivesse sido o caso, o forasteiro teria se deparado com a porta fechada do barracão até sua paciência se esgotar - mas era o forasteiro que chegou sem a intenção de dominar, sem o uso da linguagem para submeter, mas com o desejo de criar um espaço de tolerância e solidariedade, de troca, onde fosse possível fazer fluir a comunicação e, portanto, os trabalhos terapêuticos que estavam sendo propostos. Mais que isso, o forasteiro que conseguiu reconhecer algumas das contradições presentes na construção histórica de sua própria prática, para poder fazer algo diferente. Em outras palavras, não eram eles se tornando mais parecidos com a nossa equipe através do uso da psicanálise, mas eram 
os membros da equipe tornando-se mais parecidos com eles, reconhecendo-se neles através desse afeto que a linguagem, entre outros elementos, colocou em movimento.

Os problemas sociais que as pessoas identificavam e reportavam na esfera pessoal pouco a pouco deixaram de ser problema apenas deles e passaram a ser problemas de todos ali, não porque não havia o respeito pelos mandamentos que regem a transferência na clínica psicanalítica, mas porque era necessário, como argumenta Frosh (2020), não restringir as intervenções para os diversos mal-estares relatados pelos pacientes em suas análises pessoais a fatos individuais. Se o espaço sócio-político provoca perturbações nas pessoas, a tarefa do psicanalista social é ouvir essas perturbações no espaço da análise pessoal abrindo questões que possibilitem ao paciente fazer melhores acordos com a realidade social e, ao mesmo tempo, localizada a origem dessas perturbações, passa a ser imperativo que os psicanalistas as enfrentem no espaço sócio-político, ou seja, mal-estares resultantes de situações de humilhação social, preconceitos, das várias facetas da violência, desigualdade social e econômica, entre outros.

Foi nesse ponto que as demandas para os trabalhos começaram a aumentar e, com ela, a consciência de que a equipe precisaria receber novos membros. O que tentamos apontar nestas páginas, portanto, é uma reflexão sobre um trabalho em andamento, absolutamente aberto. Não deixa de ser apenas uma possibilidade a ser somada a tantos outros trabalhos, e que certamente não resolve a questão (até porque não é disso que se trata). Mas que talvez possa auxiliar no posicionamento da psicanálise frente a um horizonte de construção de algo comum.

\section{REFERÊNCIAS}

BOULOS, Guilherme Castro. Estudo sobre a variação de sintomas depressivos relacionada à participação coletiva em ocupações de sem-teto em São Paulo. 2017. Dissertação [Mestrado em Psiquiatria] - Faculdade de Medicina, Universidade de São Paulo, São Paulo, 2017

CASTRO, Silvia Elaine Santos de. Marcadores sociais da diferença: sobre as especificidades da mulher negra no Brasil. In: GT4-RACISMO, INTOLERÂNCIA e POLÍTCAS PÚBLICAS. 2011, Londrina. Marcadores sociais da diferença: as especificidades da mulher negra no Brasil. Londrina, 2011. P. 1 PDF. Disponível em: 
https://negrasoulblog.files.wordpress.com/2016/04/marcadores especificidades-damulher-negra-no-brasil >

FERENCZI, S. Princípios de relaxamento e neocatarse. [A. Cabral, Trad.]. In Psicanálise IV [pp. 53-68]. São Paulo: Martins Fontes, 1992 [1930].

FERENCZI, S. Confusão de língua entre os adultos e a criança. [A. Cabral, Trad.]. In Psicanálise IV (pp. 97- 106). São Paulo: Martins Fontes, 1992 [1933].

FREUD, S. Moral sexual 'cultural' e o nervosismo moderno In: Obras Completas, volume 08 Tradução e notas: Paulo César Souza. São Paulo: Companhia das Letras, 2015[1908] .

FREUD, S. Recordar, repetir e elaborar, In: Obras Completas, volume 10 Tradução e notas: Paulo César Souza. São Paulo: Companhia das Letras, 2010 [1914]

FREUD, S. O sentido dos sintomas. In: Obras Completas, volume 13. Tradução: Sergio Tellaroli. São Paulo: Companhia das Letras, 2014 [1917].

FREUD, S. Psicologia das massas e análise do eu. In: Obras Completas, volume 15. Tradução: Sergio Tellaroli. São Paulo: Companhia das Letras, 2011[1921].

FREUD, S. O eu e o Id. In: Obras Completas, volume 16. Tradução: Paulo César de Souza. São Paulo: Companhia das Letras, 2011[1923].

FREUD, S. A negação. [Trad. Marilene Carone] São Paulo: Cosac Naif, 2014[1925].

FREUD, S. Construções em análise. In: Obras Completas, volume 19. Tradução Paulo César de Souza. São Paulo: Companhia das Letras, 2018 [1937]. pp. 327-344.

FUREDI, F. Therapy Culture: cultivating vulnerability in an uncertain age. London: Routledge, 2004.

GAULEJAC V. Neurosis de classe. Trayectoria social y conflitos de identidade. Buenos Aires: Del Nuevo Extremo, 2013.

GONÇALVES FILHO, José Moura. Humilhação social - um problema político em psicologia. Psicol. USP, São Paulo , v. 9, n. 2, p. 11-67, 1998.

GONZÁLES, Lélia; HESENBALG, Carlos; Lugar do Negro. 3. ed. Rio de Janeiro: Editora Marco Zero Limitada, 1982.

HACKING, Ian. Mad travelers: reflections on the reality of transient mental illness. London: University Press of Virginia, 1998.

KEHL, Maria Rita. O tempo e o cão: a atualidade das depressões. São Paulo: Boitempo, 2009.

LACAN, J. Intervenção sobre a transferência. In: Escritos. Rio de Janeiro: Jorge Zahar, 1998 [1951]. pp. 214-225.

LACAN, J. O Seminário I: os escritos técnicos de Freud. Rio de Janeiro: Jorge Zahar Editora, 1986 [1953-54].

LACAN, J. A coisa freudiana. In: Escritos. Rio de Janeiro: Jorge Zahar, 1998 [1955].

LACAN, J. Direção do tratamento e os princípios de seu poder. In: Escritos. Rio de Janeiro: Jorge Zahar, 1998[1958].

LACAN, J. Séminaire 15: L'acte psychanalitique [1967-68]. Disponível em http://staferla.free.fr/S15/S15.htm 
MOUTINHO, Laura. Diferenças e desigualdades negociadas: raça, sexualidade e gênero em produções acadêmicas recentes. Cadernos Pagu, [42], 2014, 201-248. https://doi.org/10.1590/0104-8333201400420201

OSMO, Alan, \& KUPERMANN, Daniel. Confusão de línguas, trauma e hospitalidade em Sándor Ferenczi. Psicologia em Estudo, 17[2], 2012, 329-339. https://dx.doi.org/10.1590/S1413-73722012000200016

POLITZER, Georges. Crítica aos Fundamentos da Psicologia - a psicologia e a psicanálise. Trad. Marcos Marcionilo e Yvone M. T. da Silva. Piracicaba, SP: UNIMEP, 1998 [1928].

POLITZER, Georges. O fim da psicanálise [Trad. G. C. O. Silva]. Lacuna: uma revista de psicanálise, São Paulo, n. -3, p. 14, 2017 [1939]. Disponível em: https://revistalacuna.com/2017/04/28/n3-14/

ROSE, Nikolas. Our psychiatric future. The politics of Mental Health. Cambridge, UK: Polity Press, 2018.

SAFATLE, V.; DUNKER, C.; DA SILVA JUNIOR, N. Patologias do Social: arqueologias do sofrimento psíquico. Belo Horizonte: Ed. Autêntica, 2018.

SOUZA, Neusa Santos. Tornar-se negro. 2. ed. Rio de Janeiro: Edições Graal, 1983.

SEFFNER, F.; Moura, f. Percurso escolar, pluralismo democrático e marcadores sociais da diferença: necessárias negociações. In: Linguagens, Educação e Sociedade, Teresina, Ano 24, n. 41, jan./abr. 2019.

SOUZA, Neusa Santos. Tornar-se negro. 2. ed. Rio de Janeiro: Edições Graal, 1983 WEIL, Simone. O Enraizamento. São Paulo: EDUSC, 2001. 